Egyptian

Orthodontic Journal

\title{
ALKALINE PHOSPHATASE ACTIVITY IN GINGIVAL CREVICULAR FLUID IN RESPONSE TO DIFFERENT MAGNITUDES OF CONTINUOUS ORTHODONTIC FORCES
}

\author{
EMAN M. EL-SHOURBAGY*
}

\section{ABSTRACT}

The current study was undertaken to evaluate the effect of continuous force of different magnitudes $(150,50 \mathrm{~g})$ on alkaline phosphatase activity (ALP), with a focus on the amount of tooth movement after application of these forces. Eight female subjects (age range 13 to 15 years) participated in the 6 weeks study. $\mathcal{A}$ continuous retraction force of $150 \mathrm{~g}$ was applied to 1 of the maxillary canines (group I) whereas a continuous force of $50 \mathrm{~g}$ was applied to the other (group II) with a nickel-titanium closed coil spring. Gingival crevicular fluid (GCF) was collected from the mesial and distal sides of each experimental canine immediately before appliance activation and weekly over the following 6 weeks. The clinical gingival condition was evaluated at the baseline and at the end of the experiment. GCF ALP activity was determined spectrophotometrically at $37^{\circ} \mathrm{C}$ by kinetic method. The results showed insignificant changes in the clinical condition. GCF ALP activity was significantly greater in tension sites of group $I$ and $I I$ as compared with the baseline. Moreover the enzymatic activity in tension sites of group I was significantly greater than that of group II. In 6oth groups, a significant greater $A \mathcal{L} P$ activity was observed in tension sites compared with compression sites. The results showed insignificant difference in the amount of distal movement of the canines produced by the 2 forces. It was concluded that effective tooth movement can be produced with

* Associate Professor, Orthodontic Department, Faculty of Dentistry, Tanta University 
Egyptian

Orthodontic Journal

\section{lower forces and ALP activity in GCF can be considered a suitable indicator of the biologic activity in the periodontium during orthodontic tooth movement.}

\section{INTRODUCTION}

In orthodontics, mechanical stress appears to evoke biochemical and structural responses in a variety of cell types in vivo and in vitro ${ }^{1-7}$. Several hypotheses have been proposed to explain the biological basis of tooth movement induced by mechanical stress ${ }^{8-16}$. Recently, the hypothesis suggesting that a mechanical stimulus causes an inflammatory response in the periodontal tissues has received considerable attention. According to this hypothesis, inflammatory mediators are released that trigger the biological processes associated with alveolar bone resorption and apposition ${ }^{17}$. However, little information is available concerning the production of these mediators during orthodontic tooth movement in human subjects. As a result of the application of mechanical forces, the cells in the periodontal ligament (PDL) may produce sufficient amounts of mediators to diffuse into the gingival crevicular fluid (GCF).

GCF is a trasudate of the periodontal tissues, the constituents of which are derived from a variety of sources including microbial dental plaque, host inflammatory cells, host tissues and serum. In recent years, a number of these GCF constituents have shown potential as prognostic and diagnostic markers of active tissue destruction e.g. periodontal diseases ${ }^{4,18}$, but only a few studies have focused on the GCF constituents involved in bone remodeling during orthodontic tooth movement.

Bone remodeling is a coupled process in which there is co-ordinated bone resorption and formation of new bone. The process is complex, requiring interaction between different cell phenotypes, that are regulated by a variety of biochemical and mechanical factors ${ }^{19}$. Bone remodeling is regulated by systemic hormones and by local factors, which affect cells of both the osteoclast and osteoblast lineages. The local factors include growth factors, cytokines and prostaglandins $s^{20,21}$. To better describe the biological responses to orthodontic force in humans, noninvasive analysis of various cell mediators in the GCF have also been performed ${ }^{4-6,22}$.

Grieve et al ${ }^{4}$ found that prostaglandin E (PGE) and interleukin-1 $\beta($ IL-1 $\beta$ ) in gingival crevicular fluid were elevated during orthodontic tooth movement. Lowney et al ${ }^{5}$ reported that the amount of tumor necrosis factor- $\alpha(\mathrm{TNF}-\alpha)$ in

Volume 27 - June 2005 
gingival crevicular fluid was increased during such movement. Uematsu et al ${ }^{6}$ found that IL-1 $\beta$, IL-6, TNF- $\alpha$, epidermal growth factor (EGF) and $\beta_{2}$ microglobulin were significantly elevated during tooth movement compared with untreated controls. Lee et al ${ }^{22}$ evaluated the effects of a light continuous force and an interrupted force with weekly reactivation on 2 potent mediators in the bone resorption process (IL-1 $\beta$ andPGE 2 ). When a continuous force was provided, IL-1 $\beta$ and $\mathrm{PGE}_{2}$ levels showed a significant elevation at 24 hours and then decreased. With an interrupted force, significant elevations of IL-1 $\beta$ levels were observed at 24 hours and a greater significant elevation at 24 hours after the first reactivation. $\mathrm{PGE}_{2}$ levels increased significantly at 24 hours and remained high for 1 week.

Bone forming cells have been shown to have alkaline phosphatase (ALP) activity ${ }^{23}$, and changes in this enzyme level in serum and bone have been used as a markers for bone metabolism in several diseases ${ }^{24,25}$. Insoft et al ${ }^{26}$ reported that during orthodontic tooth movement, alkaline phosphatase peaked between the first and third week followed by an increase in acid phosphatase between the third and sixth weeks. This study, however was performed on 3 cases only. Perinetti et al ${ }^{27}$ used a longitudinal design to investigate alkaline phosphatase activity in GCF during orthodontic treatment in relation to the time of treatment and the type of stress exerted on the periodontium by tooth movement. There results showed that GCF ALP activity was elevated significantly in the distalized molars (DM) and contralateral molars (CM) as compared with the antagonist first molars (control) at 1,2,3 and 4 weeks. Moreover, the enzyme activity in the DMs was significantly greater than in the CMs. In the DMs, a significantly greater ALP activity was observed in sites of tension compared with sites of compression.

Tooth movement is thought to occur in 2 stages: (1) An initial mechanical compression of the periodontal ligament with minor deformation of the alveolar bone, followed by (2) a delayed metabolic response of the connective tissue. Thus, important factors for effective tooth movement include the nature of the applied force and the nature of the metabolic response in individuals during this movement.

Orthodontic forces of an impulsive nature are common and may be advantageous in inducing more physiologic tooth movement ${ }^{28,29}$; however continuous low-magnitude forces are said to be more effective at moving teeth than impulsive forces ${ }^{30,31}$. This was demonstrated recently by a clinical study ${ }^{32}$ in which magnets were used to place a continuous retraction force of $70 \mathrm{~g}$ on 1 
Egyptian

Orthodontic Journal

maxillary canine in each of 6 human subjects, while a segmental vertical loop was used to place an impulsive force on the contralateral canine in each subject. In Iwasaki et al's study ${ }^{33}$, a continuous retraction force averaging $18 \mathrm{~g}$ was applied to 1 of the maxillary canines, whereas a continuous retraction force averaging $60 \mathrm{~g}$ was applied to the other. Their results showed a statistical difference in the velocity of distal movement of the canines produced by the 2 stresses. The lag phase was eliminated and average velocities were 0.87 and 1.27 $\mathrm{mm} / \mathrm{month}$ for 18 and $60 \mathrm{~g}$ of average retraction force. As no information is available concerning ALP activity during orthodontic tooth movement in human subjects after application of continuous forces of low magnitudes. The purpose of the present study was : to obtain data concerning the response of the healthy periodontium of young individuals to relatively low $(50 \mathrm{~g})$ and relatively high $(150 \mathrm{~g})$ continuous orthodontic forces by studying the ALP activity in GCF, and to compare the effect of the different magnitudes on the amount of canine distal movement.

\section{Material and methods}

\section{Subjects}

Eight young female patients (13-15y) from the postgraduate orthodontic clinic at Tanta University were selected. All patients met the following criteria:

- The maxillary first premolars had been extracted as part of their treatment, and first stage of treatment required distal retraction of the maxillary canines.

- They were systemically healthy.

- They had not used any anti-inflammatory drugs in the month preceding the study.

- All had healthy periodontium without radiographic evidence of bone loss, minimal gingival inflammation, and probing depths less than or equal to $3 \mathrm{~mm}$ at the site of the experiment.

Oral hygiene instructions were given to all patients before start of treatment. Oral hygiene was closely monitored throughout the research period.

\section{Appliance}

All subjects received Nance or transpalatal arch on maxillary first molars. In addition, a 0.019 X 0.025 in ST ST wire was contoured and passively engaged the tube and slots of the posterior segment and laced together with ligature wire to ensure maximum anchorage. The retraction mechanism consisted of an 
initially passive auxillary wire $(0.016 \times 0.022$ in ST. ST) that was activated by a calibrated spring (Fig. 1). Two retraction forces on average 50 and $150 \mathrm{~g}$ were provided by adjusting the length of a nickel-titanium alloy closed coil spring (American Orthodontics, Sheboygan wis). One end of the spring was ligated to the hook on the buccal tube of the first molar. The other end of the spring was ligated to the hook on the auxiliary wire just distal to the maxillary canine. The springs were checked at each appointment and adjusted as needed to maintain the desired applied force magnitude.

Alginate impressions of the maxillary arch were taken and poured in stone before the appliance placement and activation and at the end of the experiment. The coronal end of the interdental papilla between the central incisors was marked with a sharp pencil. The distance between the marked point and the height of contour on the distal side of each canine ${ }^{22}$ was measured with digital caliper (Masel dental Dial caliper Bristol, USA) up to $0.01 \mathrm{~mm}$. The same measurements were made 1 week later to investigate the intra examiner error. The mean difference between the first and second readings was not statistically significant.

Plaque index $(\mathrm{PI})^{34}$, gingival index $(\mathrm{GI})^{35}$, bleeding on probing $(\mathrm{BoP})^{36}$ and pocket depth (PD) were measured. These clinical parameters were assessed twice, at the baseline and at 6 weeks.

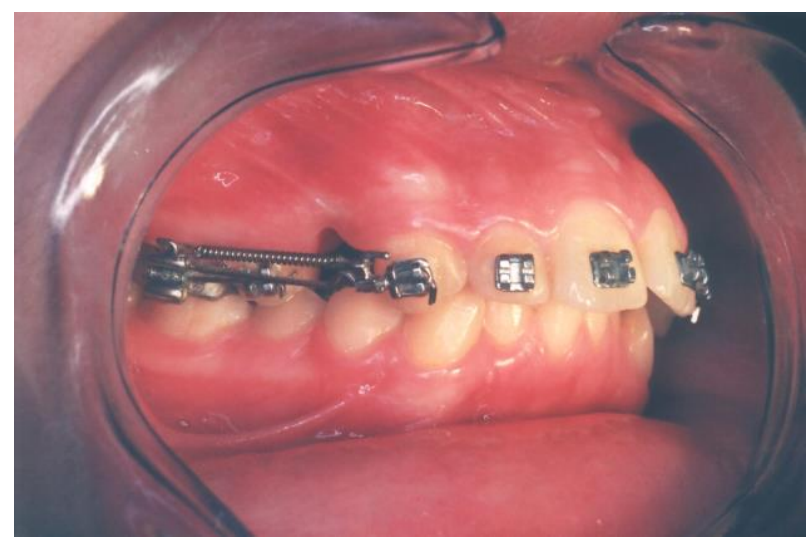

Fig. 1: Right buccal view of subject in study received continuous force with a nickeltitanium closed coil spring engaged between 2 hooks, 1 on the anchor molar and 1 on the auxiliary wire. 
Egyptian

Orthodontic Journal

GCF sampling was performed at specified times according to the following: Base line immediately before the appliance placement and activation ( 0 hour) and at 1, 2,3,4,5 and 6 weeks after initiation of canine movement.

GCF sampling was performed during the daytime because of the possible diurnal pattern of cellular activity. Before sample collection, any supragingival plaque was removed with cotton pellets. Each experimental canine was washed with water, dried gently with air and isolated with cotton rolls. No.35 standardized sterilized absorbent paper points (DiaDent group. International Inc) was carefully inserted $1 \mathrm{~mm}$ into the gingival crevice at the mesial and distal aspects of maxillary canines and allowed to remain for 60 seconds. The paper points immediately placed in sealed plastic tubes containing $200 \mu 1$ phosphate buffered saline.

\section{Alkaline phosphatase determination'}

Principle of the test :

Kinetic determination of the alkaline phosphatase based upon DGKC $^{38}$ and SCE ${ }^{39}$ recommendation

p-Nitrophenylphosphate $+\mathrm{H}_{2} \mathrm{O} \stackrel{\text { ALP }}{\longrightarrow}$ p-Nitrophenol + inorganic phosphate

\section{Reagent used:}

*Reagent1: diethanolanine buffer PH 10.2 (1.25 mmol/L) and Magnesium chloride $(0.625 \mathrm{mmol} / \mathrm{L})$

**Reagent 2 :P-Nitrophenyl phosphate $(60 \mathrm{mmol} / \mathrm{L})$

\section{Sample preparation:}

The tube containing $200 \mu \mathrm{l}$ phosphate buffered saline and the absorbent paper point was centrifuged at $400 \mathrm{~g}$ for $10 \mathrm{~min}$. and then the supernatant was separated. It can be stored at $-20^{\circ} \mathrm{C}$ until used .

\section{Procedure:}

Wave length used was $405 \mathrm{~nm}$, at $37^{\circ} \mathrm{C}$, into $1 \mathrm{~cm}$ cuvette (light bath). 1 $\mathrm{ml}$ of the reagent 1 was added to $20 \mu 1$ from the sample into the cuvette tube, mixed and incubated for one min. after that $250 \mu 1$ from the reagent 2 was added to the cuvette, mixed and incubated for one min. The changes of optical density per $\mathrm{min}$. ( $\Delta \mathrm{OD} / \mathrm{min}$.) was measured at $405 \mathrm{~nm}$. during $3 \mathrm{~min}$ (EOS-880 spectrophotometery. Italy). The results were calculated from activity of ALP $(\mathrm{U} / \mathrm{L})=\Delta \mathrm{OD} / \mathrm{min} \mathrm{X} 3424$. 
Egyptian

Orthodontic Journal

\section{Statistical analysis}

Data were collected, organized, tabulated and statistically analyzed using SPSS software version 12. Means and standard deviations of GCF ALP and clinical parameters were obtained for the two groups at the mesial and distal gingival crevice of the experimental canines. Statistical analysis was done in 3 ways: measurements at each sampling time were compared with the baseline level in each group by paired $t$ test , comparisons between tension (mesial) and compression (distal) sites for each group at each sampling time and comparisons of tension and compression sites between groups at each sampling time were made by unpaired $t$ test. Also t test was performed to compare the amount of canine distal movement between the 2 groups. Level of significant was adopted at $\mathrm{P}<0.05$.

\section{RESULTS}

All 8 participants apparently maintained good oral hygiene throughout the experiment. No significant change in PI, GI, BoP or PD was found at the end of the experiment. All the experimental sites showed good gingival and periodontal status, with PDs of 3 or less at 6 weeks. As shown in table 1; the clinical parameters had nonsignificant difference of the mean values between mesial and distal sites in the 2 groups at the baseline and at 6 weeks. At 6 weeks all clinical parameters showed slightly greater values with no significance compared with the baseline $(\mathrm{P}>0.05)$.

Table 1. Clinical parameters changes

\begin{tabular}{|c|c|c|c|c|c|c|c|c|c|}
\hline \multirow{3}{*}{ Parameters } & & \multicolumn{4}{|c|}{ Group I (150g) } & \multicolumn{4}{|c|}{ Group II (50g) } \\
\hline & & \multicolumn{2}{|c|}{ Mesial } & \multicolumn{2}{|c|}{ Distal } & \multicolumn{2}{|c|}{ Mesial } & \multicolumn{2}{|c|}{ Distal } \\
\hline & & Mean & S.D & Mean & S.D & Mean & S.D & Mean & S.D \\
\hline \multirow{2}{*}{ PI } & Baseline & 15.8 & 9.3 & 14.8 & 7.8 & 15.2 & 8.1 & 14.9 & 9.2 \\
\hline & 6 week & 20.1 & 8.4 & 18.1 & 6.5 & 19.3 & 7.6 & 17.6 & 8.2 \\
\hline \multirow{2}{*}{ GI } & Baseline & 15.5 & 8.1 & 13.9 & 7.4 & 14.3 & 7.5 & 13.8 & 8.2 \\
\hline & 6 week & 19.7 & 7.5 & 17.0 & 6.8 & 18.1 & 6.4 & 17.6 & 7.5 \\
\hline \multirow{2}{*}{ BoP } & Baseline & 15.2 & 7.3 & 14.9 & 8.4 & 14.7 & 8.5 & 14.6 & 7.2 \\
\hline & 6 week & 18.6 & 6.9 & 17.3 & 7.6 & 18.1 & 8.4 & 17.1 & 8.6 \\
\hline \multirow{2}{*}{ PD } & Baseline & 2.6 & 0.8 & 2.4 & 0.7 & 2.5 & 0.7 & 2.2 & 0.9 \\
\hline & 6 week & 3.0 & 0.6 & 2.9 & 0.7 & 2.8 & 0.9 & 2.5 & 0.8 \\
\hline
\end{tabular}

Volume 27 - June 2005 

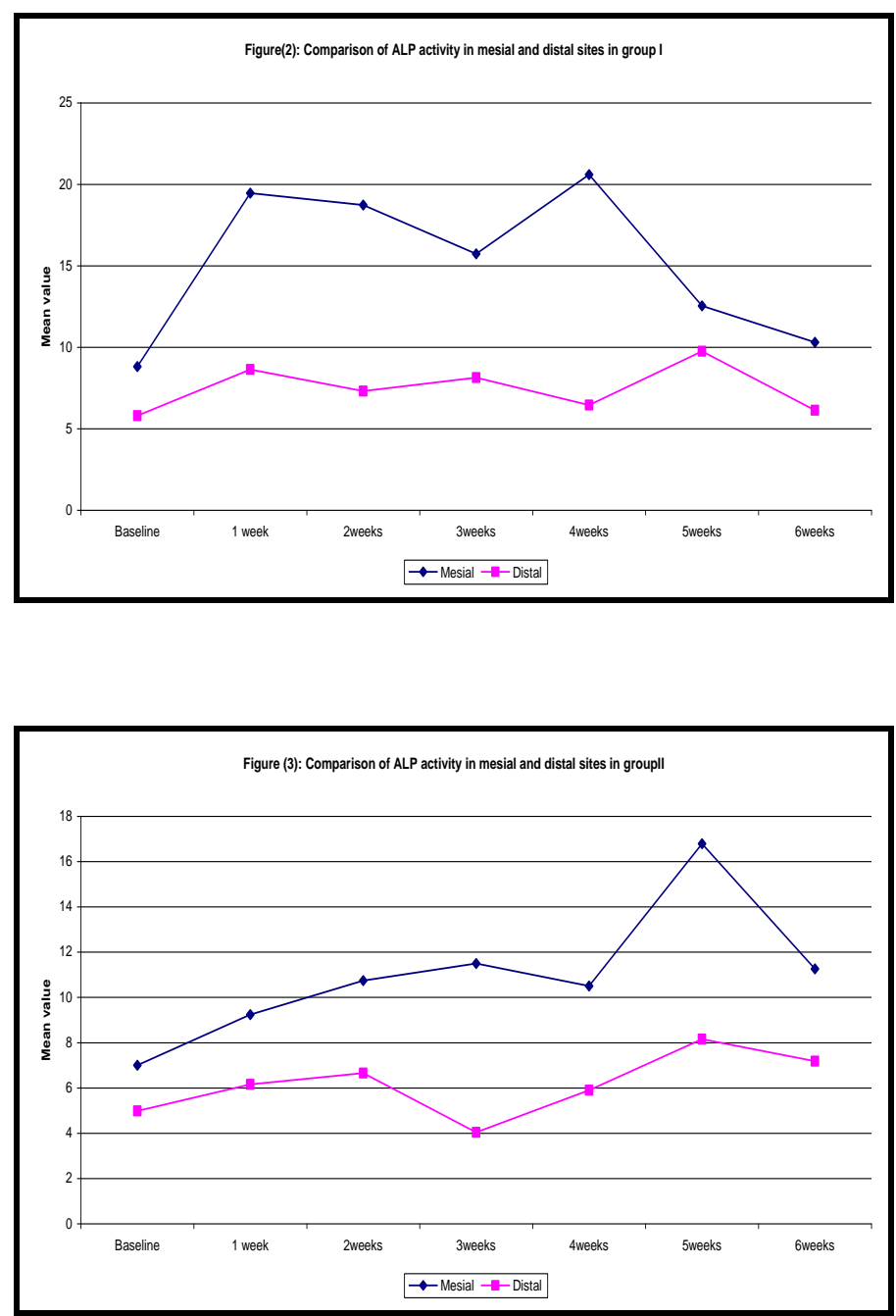

Results of pair-wise comparisons showed a significantly greater enzymatic activity in mesial sits (tension) of group I of canines retracted at high force magnitude from 1 week to 5 weeks as compared with the baseline but this became in significant thereafter, although the mean was still high. In the distal site (compression) of group I, ALP activity increased significantly at the 3 weeks compared with the baseline (Table 2, Fig. 2). 
Egyptian

Orthodontic Journal

In group II of canines retracted at low force magnitude, over the study period a significant increased ALP activity was seen in the tension sites as compared with the baseline. Significant increase of ALP activity compared with the baseline was found at 1 week and 2 weeks of the experiment in the distal site of this group (Table 2, Fig. 3)

ALP activity in the mesial site of group I was significantly greater than in the distal site of the same group at each sampling time, whereas the differences between mesial and distal site of group II were significant from week 1 to 5 being always greater in tension sites (Table 2).

In the groups comparison, in mesial sites, unpaired comparisons showed an enzymatic activity significantly greater in group I than in group II from baseline to 5 weeks. In the distal sites, statistically significant differences between group I and II were seen in week I and 3 of the experiment (Table 2)

The amounts of canine distal movement (mean \pm standard deviation) were $1.45 \mathrm{~mm} \pm 0.35$ at high force magnitude $(150 \mathrm{~g})$ and $1.26 \mathrm{~mm} \pm 0.3$ at low force magnitude. Insignificant difference was found between the 2 groups $(\mathrm{t}=1.154$, $\mathrm{P}=0.268$ ). Data were not shown in tables.

\section{DISCUSSION}

Bone is a dynamic tissue that constantly undergoes remodeling. It is thought that the major reason for remodeling is to enable the bones to respond and adapt to the mechanical stresses that occur as a result of mechanical loading during orthodontic tooth movement ${ }^{19}$.

Application of a continuous force on the crown of the tooth leads to tooth movement in the alveolus by narrowing in the periodontal ligament. Resorption of the alveolar bone in the compression site occurs because of osteoclastic activity. At the tension site, new bone formation occurs because of osteoblastic activity $^{40}$.

Bone formation results from a complex cascade of events that involves proliferation of primitive mesenchymal cells, differentiation into osteoblast precursor cells (osteoprogenitor, pre-osteoblast), maturation of osteoblasts, formation of matrix and finally mineralization ${ }^{41}$. Several of the bone-derived growth factors can cause the appearance of markers of the differentiated osteoblast precursor into mature cell, including expression of alkaline phosphatase activity, type I collagen and osteocalcin ${ }^{42}$. 
ALP is considered to be a marker of osteoblastic activity ${ }^{42-44}$ because this enzyme is essential for bone deposition ${ }^{43}$; it hydrolyzes nonorganic pyrophosphate, which is a potent inhibitor of mineralization process ${ }^{45}$.

The aim of the present study was to investigate the GCF ALP activity longitudinally during orthodontic treatment using two different magnitude of continuous retraction forces $(150,50 \mathrm{~g})$.

Analysis of GCF is a useful and advantageous method, especially for human in vivo study ${ }^{4}$; it is noninvasive, and repetitive sampling from the same site is achievable regardless of the number. This enables the monitoring of the changes at a single site during a certain period. At the beginning of this study, a baseline measurements of ALP showed little variation. However, 1 week after force application the individual variation became large enough to estimate the general response.

GCF ALP activity in this study showed significant initial peaks at 1 week after either magnitude of force was applied compared with baseline at the tension site. This was found to coincide with the findings of Perinetti et al ${ }^{27}$ who reported an increased ALP activity at 7 days. Early inflammatory processes known to occur during the early stages of orthodontic tooth movement ${ }^{4,46,47}$ may be detected in GCF as an increased alkaline phosphatase activity ${ }^{26}$. This explains why ALP values increased at 1 week as this early for osteoblastic activation.

As initially described by Rygh ${ }^{46,47}$ bone remodeling determined by tooth movement is a continuous process characterized by bone resorption in the compression sites ${ }^{46}$ and bone deposition in the tension sites ${ }^{47}$. however, recent histomorphometric findings ${ }^{48}$ have shown that this model is more complex than that described by Rygh. Both bone resorption and deposition can be present in any tension site as well as in any site of compression ${ }^{48}$. This model is based on an initially unbalanced process, in which resorption is greater than deposition and a later more balanced relationship between these phenomena ${ }^{49}$. These observations were made through stressing the alveolar bone by tooth movement in a rat model. Furthermore, King et al ${ }^{47}$ described an early phase of bone resorption ( 3 to 5 days), its reversal (5 to 7 days) in both tension and pressure sites of alveolar wall. A similar bone cycling in human has also been reported ${ }^{43,50}$. In humans, however, this timing seems to be longer than that in the rat alveolar bone. In particular, there is a sudden intial activation phase followed by resorption which can last from 10 days ${ }^{50}$ to 3 weeks $^{43}$. finally, an 80 day period is characterized by bone deposition ${ }^{50}$. These studies might therefore support the significant increase in GCF ALP in the tension site with respect to baseline for 
Egyptian

Orthodontic Journal

the entire length of the study, and the significant and insignificant increase in compression site of both groups. Also these results might be evidence that a continuous force induced continuous ALP release.

Gingival changes incident to tooth movement have been reported in both histological and ultrastructural analysis ${ }^{51}$. The subjects in the present study showed, however similar gingival conditions for the test canines in both groups at the baseline and at end of 6 weeks. This is probably due to the oral hygiene instructions given to each participant before treatment, followed by further reinforcements about gingival health throughout the treatment and because these canines are accessible and easily cleaned. It has been reported that good maintenance of clinical conditions is possible despite orthodontic appliance placement ${ }^{52,53}$. However, other studies have not shown similar results in terms of gingival conditions ${ }^{54}$. Although the differences of the clinical parameters at 6 weeks were not statistically significant compared with baseline, a slightly greater values were recorded. This minimal increase can presumably be correlated with the gingival enlargement during orthodontic treatment in other studies ${ }^{54}$.

GCF ALP activity in the tension site of group I was significantly greater than in group II from 1 week to 5 weeks. This might depend on the magnitude of force applied. This result underline the properties of the GCF ALP activity in distinguishing between the effects of different magnitude of forces.

Ren et al ${ }^{55}$ reported that minute force, leading to minute changes in pressure, might be able to switch on tooth movement. This implies that higher forces often used in orthodontic practice do not necessarily produce more efficient tooth movement. On the contrary, they might overload the periodontal tissues and cause negative effects that will hinder tooth movement. In the current study, continuous force of $150 \mathrm{~g}$ on the canine produced mean distal tooth movement of $1.45 \mathrm{~mm} / 6$ weeks. This mean was insignificantly higher than that for canine retracted with a continuous low force of $50 \mathrm{~g}$ which was 1.26 $\mathrm{mm} / 6$ weeks. Reporting on pain or discomfort perception, all patients noted that in the site of continuous low force, no pain nor discomfort was elicited while the $150 \mathrm{~g}$ continuous force site showed tender during mastication gradually subsiding and almost gone at the end of the second week. This means that continuous force of low magnitude provides effective tooth movement and painless treatment for the patients, and that higher forces do not necessarily lead to faster tooth movement. 
Egyptian

Orthodontic Journal

\section{Acknowledgment:}

I am grateful to Dr. Eman A. Tella, Associate Professor of Oral Medicine and periodontoly, Tanta University for her valuable help.

\section{REFERENCES}

1. Mostafa YA, Weaks-Dybvig M, Osdoby P. Orchestration of tooth movement. Am J Orthod 83: 245-250, 1983.

2. Davidovitch Z, Nicolay OF, Ngan PW, Shanfeld JL. Neurotransmitters, cytokines and the control of alveolar bone remodeling in orthodontics. Dent Clin North Am 32: 411-435, 1988.

3. Roberts WE, Chase CD. Kinetics of cell proliferation and migration associated with orthodontically- induced osteogenesis. J Dent Res 60: 174181,1981 .

4. Grieve WG III, Johnson GK, Moore RN, Reinhardt RA, DuBois LM. Prostaglandin E (PGE) and interleukin-1 beta (IL-1 beta) levels in gingival crevicular fluid during human orthodontic tooth movement. Am J Orthod Dentofac Orthop 105: 369-374, 1994.

5. Lowney JJ, Norton LA, Shafer DM, Rossomando EF. Orthodontic forces increase tumor necrosis factor alpha in human gingival sulcus. Am J Orthod Dentofac Orthop 108:519-524, 1995.

6. Uematsu S, Mogi M, Deguchi T. Interleukin (IL)-1 beta, IL-6, Tumer necrosis factor-alpha, epidermal growth factor and beta2-microglobulin levels are elevated in gingival crevicular fluid during human orthodontic tooth movement. J Dent Res 75:562-567, 1996.

7. Yamaguchi M, Shimizu N, Shibata Y, Abico Y. Effects of different magnitudes of tension-force on alkaline phosphatase activity in periodontal ligament cells. J Dent Res 75: 889 - 894, 1996.

8. Oppenhein A. Human Tissue response to orthodontic intervention of short and long duration. Am J Orthod Oral Surg 28: 263-301, 1942.

9. Schwarz AM. Tissues changes incident to orthodontic tooth movement. Int J Orthod 18: 331-332, 1932.

10.Goldhaber P. The effect of hypoxia on bone resorption in tissue culture. Arch Oral Biol 66: 634-641, 1958.

11.Baumrial S. A reconsideration of the propriety of the "pressure tension" hypothesis. Am J Orthod 55:12-22,1969. 
Egyptian

Orthodontic Journal

12.Epker BN, Frost H. Correlation of bone resorption and formation with the physical behavior of loaded bone. J Dent Res 44: 33-41, 1965.

13.Lilja E, Bjornestedt T, Lindskog S. Cellular enzyme activity associated with tissue degradation following orthodontic tooth movement in man. Scand J Dent Res 91: 381 - 390, 1983.

14.Davidovitch Z, Finkelson MD, Steigman S, Shanfeld JL, Montgomery PC, Korostoff E. Electric currents, bone remodling and orthodontic tooth movement. Am J Orthod 77: 14-47, 1980.

15. Yamasaki K, Shibata Y, Imia S, Tani Y, Shibasaki Y, Fukuhara T. Clinical application of prostaglandin E1 ( $\mathrm{PGE}_{1}$ ) upon orthodontic tooth movement. Am J Orthod 85: 508-518, 1984.

16. Stark T, Sinclair P. The effect of pulsed electromagnetic fields on orthodontic tooth movement. Am J Orthod 91: 91-104,1987..

17.Davidovitch Z. Tooth movement (Review). Crit Rev Oral Biol Med 2:411450,1991.

18. McCulloch CA. Host enzymes in gingival crevicular fluid as diagnostic indicators of periodontitis (Review). J Clin Periodont 21: 497-506, 1994.

19. Hill PA. Bone remodelling (Review). Br J Orthod 25: 101-107,1998.

20.Canalis E. The hormonal and local control of bone formation. Endocrine Reviews 4: 62-77, 1983.

21.21.Martin TJ, $\mathrm{Ng} \mathrm{KW}$. Mechanisms by which cells of the osteoblast lineages control osteoclast formation and activity. J Cell Biochem 56: 357-366, 1994.

22.Lee KJ, Park YC, YU HS, Choi SH, Yoo YJ. Effects of continuous and interrupted orthodontic force on interleukin $-1 \beta$ and prostaglandin $E_{2}$ production in ginival crevicular fluid. Am J Orthod Dentofac Orthop 125: 168-177, 2004.

23.Robinson R. The possible significance of hexose-phosphoric esters in ossification. Biochem J. 17:286-293, 1923.

24.Delmas PD. Clinical use of biochemical markers of bone remodeling in osteoporosis. Bone 13: 17-21, 1992.

25.Farley JR, Hall SL, Ritchie C, Herring S, Orcutt C, Miller BE. Quantification of skeletal alkaline phosphatase isoenzyme in canine serum. J Bone Miner Res 7: 779-91, 1992.

26.Insoft M, King GJ Keeling SD. The measurement of acid and alkaline phosphatase in gingival crevicular fluid during orthodontic tooth movement. Am J Orthod Dentofac Orthop 109: 287-296, 1996. 
27.Perinetti G, Paolantonio M, D'Attilio M, D'Archivio D, Tripodi D, Femminella B, Festa F, Spoto G, Alkaline Phosphatase activity in gingival Crevicular fluid during human orthodontic tooth movement. Am J Orthod Dentofac Orthop 122: 548 - 556, 2002.

28. Oates JC, Moore RN, Caputo AA. Pulsating forces in orthodontic treatment. Am J Orthod 74:577, 586, 1978.

29. Shapiro E, Roeber FW, Klempner LS. Orthodontic movement using pulsating force- induced piezoelectricity. Am J Orthod 76:59 - 66, 1979.

30.Burstone CJ, Baldwin JJ, Lawless DT. The application of continuous forces to orthodntics. Angle Orthod 31:1-14, 1961.

31.Reitan K. Biomechanical principles and reactions. In : Graber TM, Swain BF, editors. Orthodontics: Current principles and techniques. St- Louis: Mosby P. $101-192,1985$.

32.Daskalogiannakis J, Mclachlan KR. Canine retraction with rare earth magnets: an investigation of the constant force hypothesis. Am J Orthod Dentofoc Orthop 109: 489 - 495, 1996.

33.Iwasaki LR, Haach JE, Nickel JC, Morton J. Human tooth movement in response to continuous stress of low magnitude. Am J Orthod Dentofac Orthop 117: 175 - 183, 2000.

34.Silness J, Löe H. Periodontal Disease in pregnancy. II Correlation between oral hygiene and periodontal condition. Acta Odontol Scand 22: 121-135, 1964.

35.Löe H, Silness J. Periodontal disease in pregnancy I. prevalence and severity. Acta Odontol Scand. $21: 533$ - 551, 1963.

36. Ainamo J, Bay J. Problems and proposal for recording gingivitis and plaque. Inter Dent J, 25: 225-229, 1975.

37.Ramfjord SP. The Periodontal disease index J. Periodontol. 38: 602 - 622, 1967.

38. German Society of clinical chemistry, Standard method for determination of ALP activity J. Clin Chem Clin Biochem. 10: 290, 1972.

39. Scandinavian society for clinical chemistry, committee on enzymes, recommended method for the determination of four enzymes in blood J. Clin Lab Invest. 33:291,1974.

40.Graber TM, Vanarsdall RL Jr. Orthodontics. Current principles and techniques. $3^{\text {rd }}$ ed. St. Louis: Mosby; 2000. 
41.Ericksen E, Mosekilde L, Melsen F. Trabecular bone remodelling and balance in primary hyper parathyroidism. Bone 7: 213-221,1986.

42.Hill PA, Tumber A, Meikle MC. Multiple extracellular signal promote osteoblast survival and apoptosis. Endocrinology 138: 3849-3858, 1997.

43. Rodan GA. Introduction to bone biology. Bone 13: S3 - S6,1991.

44.Kuru L, Griffiths GS, Petrie A, Olsen I. Alkaline phosphatase activity is upregulated in regenerating human periodontal cells. J Periodontal Res 34: 123-127, 1999.

45.Coleman JE. Structure and mechanism of alkaline phospatase. Annu Rev Biophys Biomol Struc 21: 441-483, 1992 (Quated from Peinetti et al 2002).

46.Rygh P. Ultrastructural changes in pressure zones of rat molar periodontium incident to orthodontic movement. Acta Odont Scand 30: 575-593, 1972.

47.Rygh P. Ultrastructural changes in tension zones of rat molar periodontium incident to orthodontic movement. Am J Orthod 70: 269-281, 1976.

48.King GJ, Keeling SD, Wronski TJ. Histomorphometric study of alveolar bone turnover in orthodontic tooth movement. Bone 12: 401-409, 1991.

49.Keeling SD, King GJ, Valdez M. Serum and alveolar bone phosphatase changes reflect remodeling during orthodontic tooth movement. Am J Orthod Dentofac Orthop 103:320-326,1992.

50.Christenson RH. Biochemical markers of bone metabolism: an overview. Clin Biochem 30:573-593, 1997.

51.Redlich M, Shoshan S, Palmon A. Gingival response to orthodontic force. Am J Orthod Dentofac Orthop 116: 152-158, 1999.

52.Lundstrom F, Hamp SE. Effect of oral hygiene education on children with and without subsequent orthodontic treatment. Scand J Dent Res 88: 53-59, 1980.

53.Lundstrom F, Hamp SE, Nyman S. Systemic plaque control in children undergoing long-term orthodontic treatment. Eur J Orthod 2: 27-39, 1980.

54.Paolantonio M, Festa F, Diplacido G, D'Attilio M, Catamo G, Piccolomini R. Site-specific subgingival colonization by Actinobacillus actimomycetencomitans in orthodontic patients. Am J Orthod Dentofac Orthop 115: 486-495, 1999.

55.Ren Y, Maltha JC, Van't Hof MA, Kuijpers - Jagtman AM. Optimum force magnitude for orthodontic tooth movement: A mathematic model. Am J Orthod Dentofac Orthop 125:71-77, 2004. 